\title{
One size does not fit all: the influence of age at surgery on outcomes following Norwood operation
}

Tara Karamlou ${ }^{*}$, Kristen Sexson$^{2}$, Andrea Parrish${ }^{1}$, Karl F Welke ${ }^{3}$, D Michael McMullan ${ }^{4}$, Lester Permut ${ }^{4}$ and Gordon Cohen ${ }^{1}$

\begin{abstract}
Background: Given our large catchment area that often results in later presentation age, we sought to understand our institutional outcomes for the Norwood operation in the context of published data. Specifically, we studied whether operative and late death post-Norwood are dependent on age at operation.

Methods: Retrospective review of 105 consecutive infants undergoing Norwood (2004-2011) at our institution. Patients were divided into those undergoing Norwood $\leq 7$ days of age $(N=43 ; 41 \%)$ and those undergoing Norwood $>7$ days of age $(N=63 ; 59 \%)$. Operative mortality ( $\geq 30$ days), interstage mortality (between Norwood and superior bidirectional Glenn), STS-mortality (operative death + in-hospital death), and late mortality, occurring any time following hospital discharge were compared among groups. Multivariable factors for mortality at each time-point were compared using logistic regression models.

Results: Underlying diagnosis was HLHS in 67 (64\%) with the remainder $(N=38 ; 36 \%)$ being other single ventricle variants. Median age at surgery was 8 days (range 1-63 days) and mean weight at surgery was $3.2 \pm 0.6 \mathrm{~kg}$. Pulmonary blood flow was provided by a right ventricle-pulmonary artery conduit in $94 \%(N=99)$. Overall operative survival was $92 \%$, with $73 \%(\mathrm{~N}=66)$ undergoing bidirectional Glenn. Median age was higher for operative survivors compared to non-survivors ( 12 days vs. 5 days; $P=0.036$ ), with operative mortality higher for infants $\leq 7$ days at Norwood compared to infants $>7$ days at Norwood (14\% vs. 3\%; $P=0.04)$. After censoring for in-hospital death, age $\leq 7$ days was also associated with increased risk for late death ( $26 \%$ vs. $5 \%$; $P=0.005$ ).

Conclusions: In contrast to other institutional series, infants at our center undergoing Norwood operation at an earlier age have worse outcomes. Adoption of published practice patterns could lead to different local outcomes because of intangible center-specific effects, underscoring the principle that results from one institution may not be generalizable to others. Targeted center-specific internal review, if possible, should precede externally recommended changes in practice.
\end{abstract}

Keywords: Norwood, Single ventricle, Outcomes, Risk-factors, Congenital heart disease

\footnotetext{
* Correspondence: tara.karamlou@ucsfmedctr.org

'Division of Pediatric Cardiac Surgery, Benioff Children's Hospital, University of California, San Francisco, 513 Parnassus Avenue, Suite S-549, California, CA 94143, USA

Full list of author information is available at the end of the article
} 


\section{Background}

Investigation of the influence of surgical timing on early outcomes following operative repair for complex congenital heart disease in term neonates has not led to consensus [1-7]. Several single-center studies have found that younger age at surgery leads to improved outcomes following Norwood operation [1-7]. However, other studies have reported that younger age at surgery leads results in suboptimal physiologic parameters and higher mortality $[2,4]$. Given our large catchment area that often results in later patient age at admission, we sought to understand our institutional outcomes in context of published data and determine whether operative and late death post-Norwood were dependent on age at operation.

\section{Methods}

Approval was obtained from the institutional review board at Seattle Children's Hospital. A retrospective review of our institution's Society of Thoracic Surgeons' database identified 105 consecutive infants undergoing Norwood operation between 2004 - 2011 at Seattle Children's Hospital. Additional data pertinent to the study were abstracted from individual patient charts. Patients were included with all types of anatomy that eventuated in Norwood reconstruction as initial palliation regardless of their planned repair (univentricular versus biventricular) algorithm. Echocardiograms reviewed by a single echocardiologist (KS) to document morphology. Patients were divided into the following age groups: patients $\leq 7$ days of age at surgery and those $>7$ days of age at surgery. Because a main impetus of the current study was to test the hypothesis of generalizability using age at Norwood operation as a platform, this age cut-point was chosen to allow comparison to recently published single-institution data. Mortality was compared between groups at the following time-points: 1) operative mortality (defined as death occurring at $\leq 30$ days); 2) interstage (between Norwood and bidirectional Glenn); 3) any state mortality following discharge from hospital. In addition, because the Society of Thoracic Surgeons (STS) has recently, and appropriately for inclusive reasons, changed their preferred definition of operative mortality to: "1) all deaths, regardless of cause, occurring during the hospitalization in which the operation was performed, even if after 30 days (including patients transferred to other acute care facilities); and 2) all deaths, regardless of cause, occurring after hospital discharge, but before the end of the $30^{\text {th }}$ postoperative day", we tabulated mortality in accordance with this definition. Multivariable logistic regression analysis determined riskfactors for mortality at these three cross-sectional timepoints. Significance was considered to be $P<0.05$. SAS software, version 9.3 (Cary, NC) was used for all analyses.

\section{Results}

\section{Patients}

We identified 105 patients from our institution that met the eligibility criteria over the study period. Underlying diagnosis was hypoplastic left heart syndrome (HLHS) in 67 (64\%) with the remainder $(\mathrm{N}=38 ; 36 \%)$ being other single ventricle variants. Median age at surgery was 8 days (range 1-63 days) and mean weight at surgery was $3.2 \pm$ $0.6 \mathrm{~kg}$. Pulmonary blood flow was provided by a right ventricle-pulmonary artery conduit in $94 \%(\mathrm{~N}=99)$. Forty three (41\%) of patients were $\leq 7$ days and 62 (59\%) were $>7$ days at the time of Norwood reconstruction. Median age for those $\leq 7$ days was 5 days (range 1-7), and 12 days (range 8-63) for those $>7$ days of age. Patient characteristics differed slightly among groups, Table 1 . Importantly, preoperative creatinine was higher and there were a greater number of patients with hypoplastic left heart syndrome (HLHS) among those patients $\leq 7$ days of age compared to the older neonates. There was a trend toward a higher prevalence of noncardiac anomalies and a higher preoperative hematocrit among the younger neonates compared to those $>7$ days of age, though statistical significance was not reached. The median age of patients was lower (5 days) for patients who died at $\leq 30$ days compared to those who survived (12 days).

\section{Patient outcomes}

A flow chart of patient events following Norwood is shown in Figure 1. Overall there were 26 deaths (25\%). Twentyone deaths were among patients operated on within the first 3 years, with only 5 deaths since 2008. Three patients died ( 2 in-hospital and 1 late) following transplantation. Operative mortality was $8 \%(n=8)$ and was significantly lower for those patients undergoing Norwood at $>7$ days of age compared to the younger neonates, Figure 2. Inhospital mortality was $11 \% \quad(n=12)$. Using the STS

\section{Table 1 Patient characteristics}

\begin{tabular}{|c|c|c|c|}
\hline Variable & $\begin{aligned} & \leq 7 \text { days } \\
N & =43(41 \%)\end{aligned}$ & $\begin{array}{c}>7 \text { days } \\
N=62(59 \%)\end{array}$ & P-value \\
\hline Female & $44 \%$ & $43 \%$ & 0.87 \\
\hline $\begin{array}{l}\text { Weight at } \\
\text { operation (kg) }\end{array}$ & $3.2 \pm 0.5$ & $3.2 \pm 0.6$ & 0.97 \\
\hline $\begin{array}{l}\text { Preoperative } \\
\text { creatinine (mg/dl) }\end{array}$ & $0.6 \pm 0.1$ & $0.5 \pm 0.1$ & 0.02 \\
\hline Preoperative hematocrit (\%) & $42 \pm 5$ & $40 \pm 6$ & 0.05 \\
\hline H LHS & $77 \%$ & $55 \%$ & 0.02 \\
\hline Non-cardiac anomaly & $16 \%$ & $5 \%$ & 0.05 \\
\hline AW moderate or greater & $9.5 \%$ & $22 \%$ & 0.26 \\
\hline Prenatal diagnosis & $81 \%$ & $59 \%$ & 0.01 \\
\hline Restrictive atrial septum & $32 \%$ & $21 \%$ & 0.25 \\
\hline $\begin{array}{l}\text { Pulmonary venous } \\
\text { obstruction }\end{array}$ & $0 \%$ & $4 \%$ & 0.31 \\
\hline
\end{tabular}




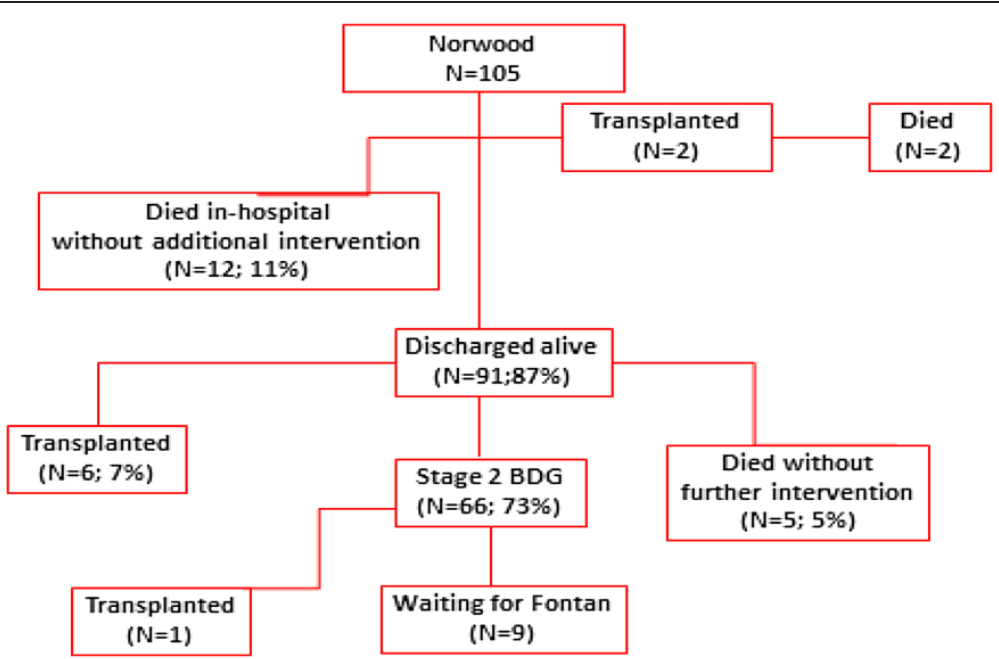

Figure 1 Flow-chart of events for 105 infants undergoing Norwood operation. BDG, bidirectional Glenn.

definition for operative mortality, there were 14 (13\%) deaths. There was a trend toward lower STS-defined mortality among the older patients $[10 \%(6 / 62)$ for patients $>7$ days of age vs. $19 \%$ (8/43) for patients $\leq 7$ days of age; $P=0.18\}$, though statistical significance was not reached. Similarly, overall any-state death post discharge was also significantly lower for patients $>7$ days of age (5\%) vs. those $\leq 7$ days (26\%), $P=0.005$, Figure 3 . While not statistically significant, interstage death $(16 \%$ overall $)$ also tended to be lower for patients $>7$ days of age (11\%) vs. those $\leq 7$ days $(23 \%), P=0.10$.

\section{Multivariable risk-factors}

We were not able to identify any multivariable factors for death at any of the time-points examined. Importantly, neither a diagnosis of HLHS, year of surgery, the presence of noncardiac anomalies (both of which were

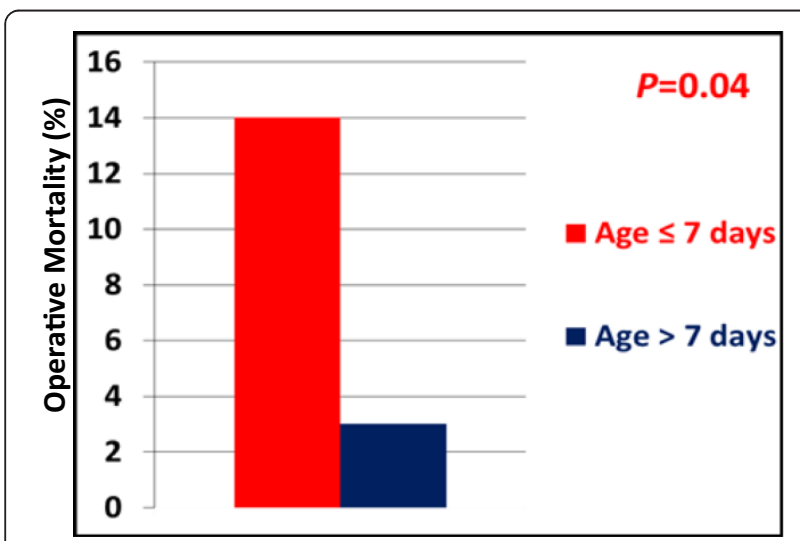

Figure 2 Histogram showing operative mortality ( $\leq 30$ days) for patient groups. Infants undergoing Norwood operation (red bar) $\leq 7$ days had significantly higher mortality compared to those $>7$ days of age at Norwood (blue bar). more prevalent in the younger cohort), nor younger age at surgery were associated with mortality at any timepoint.

\section{Discussion}

Our study, using age at surgery as a platform, illustrates the concept that recommendations based on results at one institution may not be generalizable to another institution. We have shown that infants undergoing Norwood operation at age $>7$ days of age have improved early and intermediate outcomes compared to those infants undergoing surgery at age $\leq 7$ days. While we are not advocating delaying operative intervention beyond 12 days (which was the median age among our older

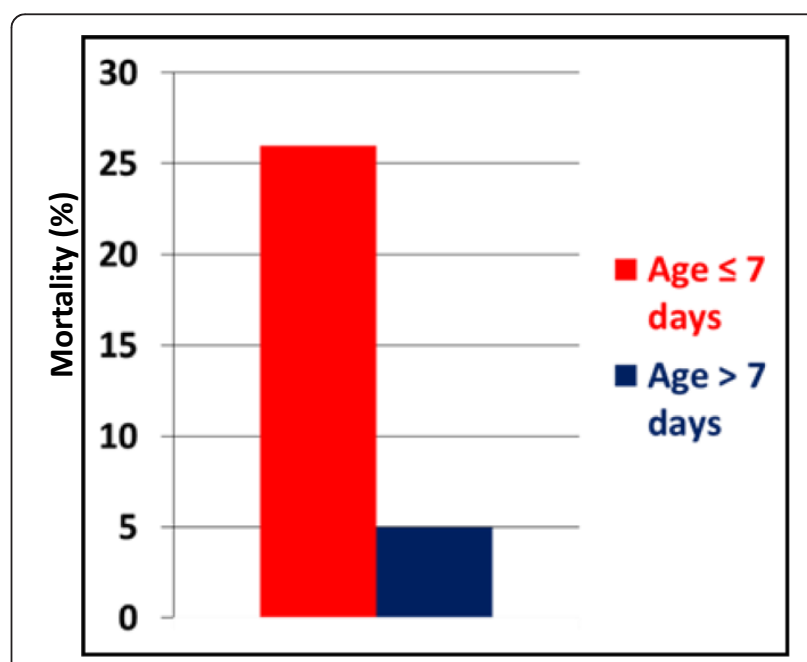

Figure 3 Histogram showing mortality at any time following hospital discharge for patient groups. Infants undergoing Norwood operation $\leq 7$ days (red bar) had significantly higher mortality compared to those $>7$ days of age at Norwood (blue bar) 
subgroup), the present data do suggest that variation in practice patterns (so-called intangible factors including differences in ICU care or operative management) may preclude direct translation of treatment guidelines between centers. An earlier report from our institution demonstrated that univentricular palliation in infants could be performed in infants $>30$ days of age with acceptable results (zero in-hospital mortality) [8]. Importantly, two of the 9 patients in this small case series died following bidirectional Glenn. We acknowledge that late outcomes are incompletely studied in the present study due to the immature state of the cohort. While our operative mortality (9.7\%) and interstage mortality (16\%) rates are comparable to other contemporary results [9-12], including those from the recently published Single Ventricle Reconstruction Trial (11.5\% for 30-day mortality and $12 \%$ for interstage mortality, respectively), there could be higher late attrition related to age at initial Norwood. Our results are in contrast to previously published studies, many of which showed older age to be an important risk-factor for post-Norwood mortality [3-7]. Alsoufi et al. [4] reported outcomes from 55 infants older than 14 days at their center. They found that age $<3$ weeks at Norwood was a risk factor for both mortality prior to bidirectional Glenn and for overall mortality, but that those infants $>2$ weeks required pulmonary vasodilators and higher inotropic support that translated into ongoing attrition following bidirectional Glenn [4]. Similarly, Hehir et al. [3] studied 313 hospital survivors following Norwood operation at the Children's Hospital of Philadelphia. They showed that age at operation $>7$ days was a risk-factor for interstage death. Importantly, the presence of intact atrial septum, which was more prevalent in the older infants, was also strongly associated with interstage death. An older report from Mahle and colleagues [5], also from the Children's Hospital of Philadelphia, found that age $>14$ days at surgery was associated with higher mortality following Norwood.

Determining a physiologic or rational explanation for our results is challenging in the context of a retrospective study in which treatment patterns ostensibly changed during the course of the study. Inadequate statistical power precluded a fruitful multivariable analysis that included both era as well as the other anatomic and ypsiologic parameters. Results at our institution undoubtedly improved over the study period despite year of surgery being an insignificant univariable predictor of outcomes. Regarding potential physiologic influences, Tweddell and colleagues reported that neonates undergoing Norwood operation earlier than 8 days of age had lower superior vena cava saturations (as a surrogate for mixed venous saturations) and wider arterial-venous oxygen difference in the first 48 hours following Norwood reconstruction.
It is possible that older neonates had improved systemic-pulmonary flow matching due to a less dynamic pulmonary vascular bed. It is also possible that younger patients had a trend toward a higher prevalence of noncardiac anomalies as well as a higher prevalence of an underlying diagnosis of HLHS, which, in other studies have led to worse outcomes following Norwood reconstruction $[9,12]$.

\section{Limitations}

The results reported are from a retrospective review of a prospectively maintained institutional dataset. Furthermore, due to a paucity of events, we were unable to identify multivariable factors associated with outcome. Our selected groups differed with respect to specific factors (including an underlying diagnosis of HLHS) that could have biased results in favor of the older cohort. However, these specific factors also were not identified to be informative with respect to outcome in our univariable analysis. Similarly, though year of surgery was not significant in univariable analysis, results clearly improved over time indicating that era may have been an important factor. Our dichotomization of the variable age, though apparently arbitrary, was pragmatic, insofar as it was chosen to allow comparison to other previous published studies while allowing enough patients in each group. Finally, later outcomes, which arguably could be adversely impacted by later age, were incompletely studied in the present report.

\section{Conclusion}

In contrast to other institutional series, infants at our center undergoing Norwood operation at an earlier age have worse outcomes. Adoption of published practice patterns could lead to different local outcomes because of intangible center-specific effects, underscoring the principle that results from one institution may not be generalizable to others. Targeted center-specific internal review, if possible, should precede externally recommended changes in practice.

\section{Abbreviations}

STS: Society of Thoracic Surgeons; HLHS: Hypoplastic left heart syndrome.

\section{Competing interests}

The authors declare that they have no competing interests.

\section{Authors' contributions}

All authors shared in the conception and execution of the study. TK completed the data analysis, primarily authored the manuscript, and was responsible for completing the revisions and submitting the manuscript. KW and AP assisted with the statistical analysis and critically reviewed the manuscript and made editorial changes. AP was also involved in abstracting and interpreting the data sets. KS performed all of the echocardiographic reviews and entered all of the offline echocardiographic information into the data spreadsheet. DM, LP and GC were responsible for idea conception, manuscript preparation, editing, and for final interpretation of the data. All authors read and approved the final manuscript. 


\section{Acknowledgements}

There are no funding sources to disclose for the authors.

\section{Author details}

'Division of Pediatric Cardiac Surgery, Benioff Children's Hospital, University of California, San Francisco, 513 Parnassus Avenue, Suite S-549, California, CA 94143, USA. ${ }^{2}$ Division of Pediatric Cardiology, Texas Children's Hospital, Houston, TX, USA. ${ }^{3}$ Division of Pediatric Cardiac Surgery, Children's Hospital of Illinois, Peoria, II, USA. ${ }^{4}$ Section of Pediatric Cardiothoracic Surgery, University of Washington School of Medicine and Seattle Children's Hospital, Seattle, WA, USA.

Received: 5 July 2013 Accepted: 5 May 2014

Published: 14 June 2014

\section{References}

1. Ashburn DA, McCrindle BW, Tchervenkov Cl, Jacobs ML, Lofland GK, Bove EL, Spray TL, Willimas WG, Blackstone EH for the members of the Congenital Heart Surgeons Society: Outcomes after the Norwood operation in neonates with critical aortic stenosis or aortic valve atresia. J Thorac Cardiovasc Surg 2003, 125:1070-1082.

2. Tweddell JS, Hoffman GM, Fedderly RT, Ghanayem NS, Kampine JM, Berger S, Mussatto KA, Litwin BS: Patients at risk for low systemic oxygen delivery after the Norwood procedure. Ann Thorac Surg 2000, 69:1893-1899.

3. Hehir DA, Dominguez TE, Ballweg JA, Ravishankar C, Marino BS, Bird GL, Nicolson SC, Spray TL, Gaynor JW, Tabbutt S: Risk factors for interstage death after stage 1 reconstruction of hypoplastic left heart syndrome and variants. J Thorac Cardiovasc Surg 2008, 136:94-99.

4. Alsoufi B, Manlhiot C, Al-Ahmadi M, Al-Halees Z, McCrindle BW, Mousa AY, Al-Heraish Y, Kalloghlian A: Older children at the time of Norwood operation have ongoing mortality that continues after cavopulmonary connection. J Thorac Cardiovasc Surg 2011, 142:142-147.

5. Mahle WT, Spray TL, Wernovsky G, Gaynor JW, Clark BJ: Survival after reconstructive surgery for hypoplastic left heart syndrome. Circulation 2000, 102(suppl 3):||l136-|||141.

6. Bove EL, Lloyd TR: Staged reconstruction for hypoplastic left heart syndrome: contemporary results. Ann Surg 1996, 224:387-394.

7. Ashburn DA, Blackstone EH, Wells WJ, Jonas RA, Pigula FA, Manning PB, Lofland GK, Williams WG, McCrindle BW: Determinants of mortality and type of repair in neonates with pulmonary atresia and intact ventricular septum. J Thorac Cardiovasc Surg 2004, 127:1000-1007.

8. Duncan BW, Rosenthal GL, Jones TK, Lupinetti FM: First-stage palliation of complex univentricular cardiac anomalies in older infants. Ann Thorac Surg 2001, 72:2077-2080

9. Jacobs JP, O'Brien SM, Pasquali SK, Jacobs ML, Lacour-Gayet FG, Tchervenkov Cl, Austin EH 3rd, Pizarro C, Pourmoghadam KK, Scholl FG, Welke KF, Gaynor JW, Clarke DR, Mayer JE Jr, Mavroudis C: Variation in benchmark operations: an analysis of the Society of Thoracic Surgeons Congenital Heart Surgery Database. Ann Thorac Surg 2011, 92:2184-2192.

10. Ghanayem NS, Hoffman NS, Mussatto KA, Cava JR, Frommelt PC, Rudd NA, Steltzer MM, Bevandic SM, Frisbee SS, Jaquiss RD, Litwin SB, Tweddell JS: Home surveillance program prevents interstage mortality after the Norwood procedure. J Thorac Cardiovasc Surg 2003, 126:1367-1377.

11. Ghanayem NS, Allen KR, Tabbutt S, Atz AM, Clabby ML, Cooper DS, Eghtesady P, Frommelt PC, Gruber PJ, Hill KD, Kaltman JR, Laussen PC, Lewis $A B$, Lurito KJ, Minich LL, Ohye RG, Schonbeck JV, Schwartz SM, Singh RK, Goldberg CS, Pediatric Heart Network Investigators: Interstage mortality after the Norwood procedure. Results of the multicenter Single Ventricle Reconstruction Trial. J Thorac Cardiovasc Surg 2011, 144:896-906.
12. Tabbutt S, Ghanayem N, Ravishankar C, Sleeper LA, Cooper DS, Frank DU, Lu M, Pizarro C, Frommelt P, Goldberg CS, Graham EM, Krawczeski CD, Lai WW, Lewis A, Kirsh JA, Mahony L, Ohye RG, Simsic J, Lodge AJ, Spurrier E, Stylianou M, Laussen P, Pediatric Heart Network Investigators: Risk factors for hospital morbidity and mortality after the Norwood procedure: a report from the Pediatric Heart Network Single Ventricle Reconstruction trial. J Thorac Cardiovasc Surg 2012, 144:882-895.

doi:10.1186/1749-8090-9-100

Cite this article as: Karamlou et al:: One size does not fit all: the influence of age at surgery on outcomes following Norwood operation. Journal of Cardiothoracic Surgery 2014 9:100

\section{Submit your next manuscript to BioMed Central and take full advantage of:}

- Convenient online submission

- Thorough peer review

- No space constraints or color figure charges

- Immediate publication on acceptance

- Inclusion in PubMed, CAS, Scopus and Google Scholar

- Research which is freely available for redistribution

Submit your manuscript at www.biomedcentral.com/submit
C Biomed Central 